RESEARCH ARTICLE

\title{
Synthesis of cisplatin encapsulated zinc oxide nanoparticles and their application as a carrier in targeted drug delivery
}

\author{
H.M.I. Abayarathne ${ }^{1}$, S.P. Dunuweera ${ }^{2}$ and R.M.G. Rajapakse, ${ }^{1, *}$ \\ ${ }^{1}$ Department of Chemistry, University of Peradeniya, Peradeniya 20400, Sri Lanka. \\ ${ }^{2}$ Department of Chemistry, Temple University, 1901N, 13th St, Philadelphia, PA 19122, USA.
}

Received: 31/05/2019 ; Accepted: 16/01/2020

\begin{abstract}
Cisplatin is a frequently used anticancer drug that has been developed as the first platinum-based anticancer drug. The cis configuration enables the coordination complex to be covalently binding to one or two DNA strands and thus crosslinking the DNA strands, causing the cells to die in a programmed manner. Cisplatin is administered as an IV infusion in saline solution for medication of solid malignity. Anticancer drugs usually have a variety of side effects, but an encapsulation of the drug in a suitable host material minimizes the side effects while improving the efficacy of the drug due to its slow release only at the target. The aim of this research is to develop a simple, but effective mechanism for the preparation of porous zinc oxide nanoparticles (PZnO NPs) using the forced hydrolysis method reaction of zinc acetate dihydrate with deionized water in diethylene glycol (DEG) media. This synthesized PZnO NPs were then characterized by Scanning Electron Microscopy (SEM), Energy Dispersive X-Ray Analysis (EDX), Fourier Transform Infrared Spectroscopy (FT-IR), Particle Size Analysis and Powder $\mathrm{X}$-Ray Diffraction (PXRD). The encapsulation of cisplatin within the porous zinc oxide nanoparticles was confirmed by X-ray Fluorescence (XRF), SEM, EDX, and FT-IR studies. Our results show that the synthesized nanoparticles have the hexagonal wurtzite structure as confirmed by PXRD. The average particle size as determined by light scattering is $52.4 \pm 0.1 \mathrm{~nm}$ SEM images show porous spherical morphology with aggregated particles. XRF data of the cisplatin encapsulated product show a Pt: $\mathrm{Cl}$ ratio of 1:2 showing cisplatin encapsulation without any fragmentation or other chemical change. The presence of $\mathrm{NH}_{3}$ in the encapsulated product is also apparent from FT-IR data. The encapsulation of the anti-cancer drug cisplatin to PZnO NPs and its $\mathrm{pH}$ dependence on the release of the drug from PZnO NPs was studied by measuring the amount of Pt released as a function of the time which was done using Inductively Coupled Plasma Atomic Emission Spectroscopy (ICP-AES) at $\lambda_{\max } 265.94 \mathrm{~nm}$. The encapsulation efficiency of Cisplatin into PZnO NPs was found to be $50.52 \%$. The percentage of Cisplatin released from PZnO NPs during the first 7 hours was $<6.30 \%$ in the acetate/ phosphate buffer at $\mathrm{pH} 4.0,5.0,6.0,7.0$ and 8.0. The maximum release of $8.64 \%$ was observed at $\mathrm{pH}=6.0$ after 24 hours.
\end{abstract}

Keywords: Anticancer drug; cisplatin; encapsulation; porous zinc oxide nanoparticles; slow release.

\section{INTRODUCTION}

Zinc oxide occurs as a mineral zincite in nature and is the most important zinc compound with many industrial applications. The pigment in white paints is zinc oxide and is used in the production of enamels, white inks, white glue, opaque glasses, rubber products, and floor tiles, and many other products. It is also used in cosmetics, soaps, pharmaceuticals, dental cements, batteries, electrical equipment, and in piezoelectric equipment. Other applications are as a flame retardant, plastic UV absorber and a reagent in analytical chemistry and in the preparation of the majority of zinc salts. The compound is used in medicine as an antiseptic, astringent, and topical protector (Moezzi et al., 2012; Jiang et al., 2018). ZnO has three crystal structures: hexagonal wurtzite, cubic zinc-blende and a rarely observed cubic rock-salt type. The most thermodynamically stable structure, under ambient conditions, is the wurtzite form (Ashrafi and Jagadish, 2007). The zinc-blend structure is metastable and can only be stabilized on cubic substrates by epitaxial growth, whereas the cubic rock-salt structure is usually only stable under extreme pressure (Özgür et al., 2005). $\mathrm{ZnO}$ is a common material used in nanotechnology and versatile architectures of $\mathrm{ZnO}$ can be easily synthesized simply by wet-chemical and autoclaving or hydrothermal technologies. The use of zinc oxide nanoparticles in cancer has been well investigated in various biomedical applications. Anticancer activity of $\mathrm{ZnO}$ NPs has been demonstrated through the generation of ROS and also through apoptosis (Rasmussen et al., 2010; Qu and Morais, 2001). However, zinc is needed for the action of more than 300 enzymes; as such, it is involved in many of the body's enzymatic and metabolic functions. There are more than 2,000 transcription factors in gene expression that enable zinc to retain its structural integrity and bind to DNA (Prasad, 1998; Prasad, 1993). Zinc's role in cancer has now been developed in human studies as a link between zinc deficiency and cancer. Compared to healthy people, zinc status is now reported to be compromised in cancer patients. Several researchers reported a drop of zinc in plasma of cancer patients (Inutsuka and Araki, 1978). The decrease in plasma zinc in cancer is believed to be due to 
increased tumor requirements of the element, especially when the tumors have a high DNA synthesis rate, which is partly dependent on zinc (Abnet et al., 2005; Lee et al., 2004; Prasad et al., 1998 and Abdulla, 1979). Zinc is necessary for normal tissue proliferation, but opinions differ on the role of zinc in the induction and proliferation of malignant cells. A high intake of zinc has been reported to reduce the incidence of some malignant tumors such as stomach and esophageal cancers (Fong et al., 1996; Fong et al., 1997; Newberne et al., 1997 and Grattan and Freake, 2012). In addition, electrostatic properties are another useful feature of ZnO NPs. This property is used for demonstrate anti-cancer activity where ZnO NPs exhibit a different type of surface charge behavior due to the presence of chemisorbed neutral hydroxyl groups. Protons move out of the particle surface in an aqueous medium at high $\mathrm{pH}$, leaving a negatively charged surface with partially bonded oxygen atoms $\left(\mathrm{ZnO}^{-}\right)$. Protons from the environment are transferred to the particle surface at low $\mathrm{pH}$, leading to a charged positive surface $\left(\mathrm{ZnOH}_{2}^{+}\right)$ (Degen and Kosec, 2000). In physiological conditions, these nanoparticles carry a strong positive surface charge (Abercrombie and Ambrose, 1962). However, cancer cells have a high concentration of anionic phospholipids (phosphatidylserine) on their external membranes and have great potential for negative membranes (Vallabhapurapu et al., 2015). Hence, cancer cells can electrostatically interact with positively charged ZnO NPs. This interaction promotes the cellular absorption, phagocytosis, and cytotoxicity of these nanoparticles (Biplab et al., 2016). $\mathrm{ZnO}$ NPs has also been investigated for the loading of drugs for better cellular absorption and synergistic activity. $\mathrm{ZnO}$ NP surface modifications have been carried out to further improve its stability and increase the selectivity of specific cells. Given all aspects, PZnO NPs are one of the most promising materials for clinical use in cancer treatment as they demonstrate a significantly higher loading capacity than other organic systems, such as micelles, liposomes, polymersomes or, possibly, non-porous inorganic materials (Beletsi et al., 2008; Gryparis et al., 2007), the solid nature of the carrier provides the trapped species with a high level of protection against external aggression and the deficiency of zinc can be managed. The aim of this research is to develop a simple, but effective mechanism for the preparation of porous zinc oxide nanoparticles (PZnO NPs) using the forced hydrolysis reaction of zinc acetate dihydrate with deionized water in diethylene glycol (DEG) media. The well-characterized synthesized nanoparticles were used to encapsulate the anticancer drug cisplatin. The cisplatin's ability to damage DNA is shown in Figure 1.

Cisplatin is a small drug molecule which contains a platinum (II) ion in the middle of a flat square with two chloride ions and two ammonia molecules making up the corners in cis configuration. It is approved for human use in 1978 and it was the first of a completely new type of anticancer drug that based on coordination complex. It is extremely effective and is a common treatment for testicular and ovarian cancers (Sadler and Guo, 1998). The cis configuration (Figure 2a) enables the coordination complex to be covalently binding to one or two DNA strands and thus cross-linking the DNA strands, causing the cells to die in a programmed manner. The alternative isomer, transplatin (Figure 2b), is not a useful drug and is supposed to be disabled before reaching DNA (Rajapakse and Dunuweera, 2017).

However, cisplatin has some side effects such as changes in the taste of food, diarrhea, kidney damage, nerve damage, nausea and vomiting, hearing loss, hair loss and a decrease in blood cell production in the bone marrow (Astolfi et al., 2013; Oun et al., 2018). In order to limit these toxic effects of cisplatin, we have developed a method in which cisplatin is encapsulated in porous $\mathrm{ZnO}$ NPs for targeted delivery to cancerous cells and to slow release,

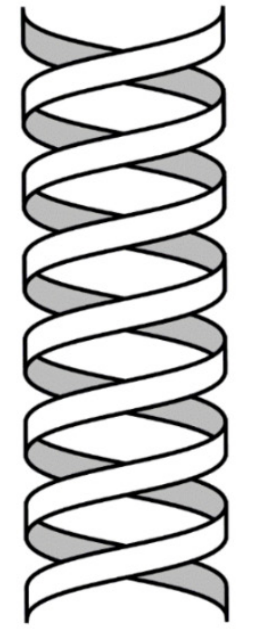

DNA Double helix

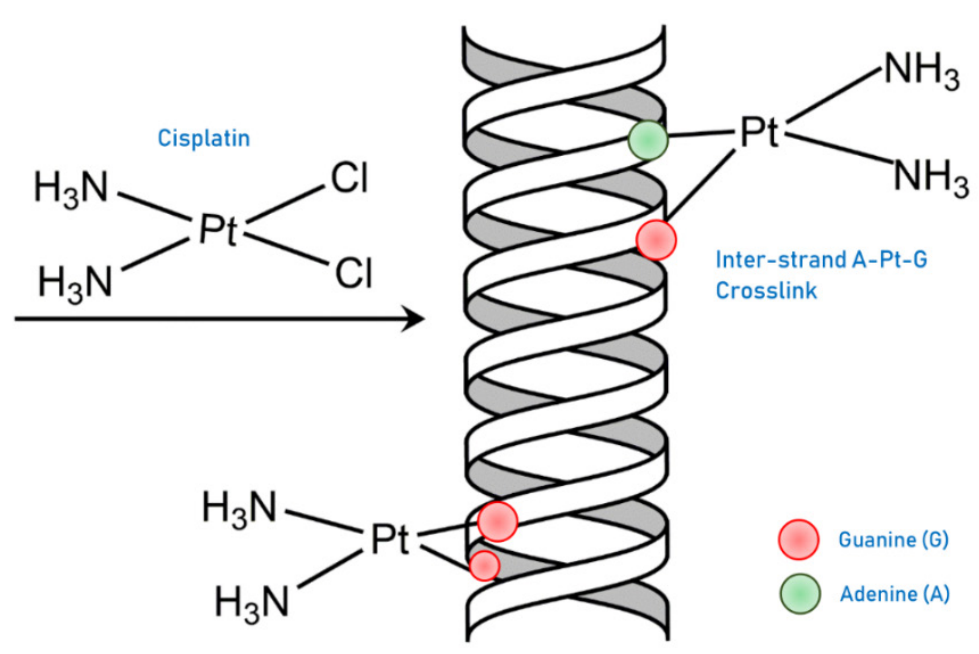

Intra-strand G-Pt-G Crosslink

Figure 1: Illustration of DNA damaging mechanism of cisplatin. Cisplatin binds to Adenine (A) and Guanine (G) N atoms in interstand and intra-stand A-Pt-G crosslink thus damaging DNA. 


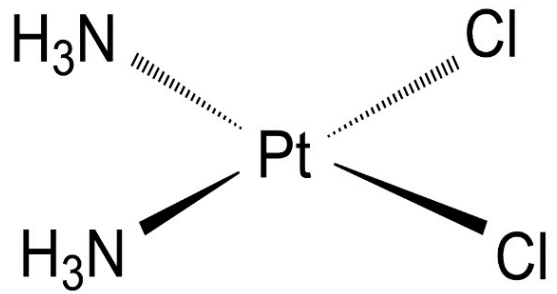

(a)

Figure 2: Chemical structures of (a) cisplatin and (b) transplatin.

only at their vicinity. The main hypothesis of this work is that under low $\mathrm{pH}$ conditions prevailing in cancer cells $\mathrm{ZnO}$ dissolves slowly releasing cisplatin, only at the vicinity of cancer cells, whereas $\mathrm{ZnO}$ is stable at physiological $\mathrm{pH}$ values of blood and healthy cell media. In this way, only the minimum dosage required can be targeted towards cancer cells, avoiding its toxic effects on healthy normal cells and increasing the bioavailability and efficacy of the drug. In fact, we are the pioneers in using non-toxic porous inorganic oxide and carbonate nanomaterials for targeted delivery of anticancer drugs for slow- and steady-release only at the cancerous cells (Dunuweera and Rajapakse, 2016; Ranathunge et al., 2019; Dunuweera and Rajapakse, 2017 and Weerasuriya et al., 2017). There we used $\mathrm{CaCO}_{3}$, $\mathrm{MgO}$ and hydroxyapatite nanomaterials as drug carriers. All of them were successful in $\mathrm{pH}$ triggered drug release only at the cancerous cells with the additional benefit of supplying essential metal ions such as $\mathrm{Ca}^{2+}$ and $\mathrm{Mg}^{2+}$ to cancer patients. This is the first time study of use of $\mathrm{ZnO}$ nanomaterials for the same purpose where it also has the additional benefit of supplying essential $\mathrm{Zn}$ to the cancer patients to circumvent the problem of zinc deficiency usually encountered in them and to use zinc as a therapeutic agent also.

\section{MATERIALS \& METHODS}

\section{Materials}

Zinc acetate dihydrates $\left[\mathrm{Zn}\left(\mathrm{CH}_{3} \mathrm{COO}\right)_{2} \cdot 2 \mathrm{H}_{2} \mathrm{O}\right]$, diethylene glycol (DEG), cisplatin $\left[\right.$ cis- $\left.\mathrm{PtCl}_{2}\left(\mathrm{NH}_{3}\right)_{2}\right]$ were the main chemicals used. All the chemicals except cisplatin were of analytical grade and were purchased from Sigma-Aldrich and used without further purification. Cisplatin injection bottles containing $1 \%$ cisplatin in saline water was purchased from Sri Lanka Pharmacy, Kandy, Sri Lanka.

\section{Synthesis and Characterization of PZnO NPs}

Porous zinc oxide nanoparticles were synthesized using the forced hydrolysis method (Eixenberger et al., 2017). Zinc acetate dihydrate $(1.000 \mathrm{~g})$ was added to diethylene glycol (DEG), (100 mL), and the solution was brought to $85^{\circ} \mathrm{C}$. Next Deionized water $(0.30 \mathrm{~mL})$ was added, and the solution was heated to $155{ }^{\circ} \mathrm{C}$ and held for 2 hours while stirring $(300 \mathrm{rpm})$. Upon cooling to room temperature, the product was collected by centrifugation at $5000 \mathrm{rpm}$, subsequently washed several times with ethanol, and the product obtained was dried for 24 hours at $60^{\circ} \mathrm{C}$ in an oven. Then, the final product was calcined at $500{ }^{\circ} \mathrm{C}$ for 5 hours.

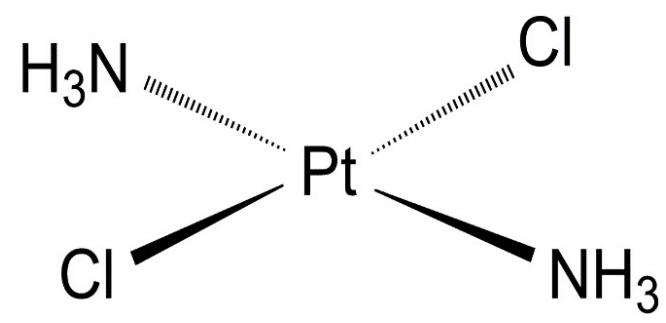

(b)

PZnO NPs thus obtained were characterized by PXRD (Siemens D5000 powder X-ray diffractometer), Laser Light Scattering based Particle Size Analysis (CILAS Particle Size Analyzer NANO DS), FT-IR (Shimadzu IR-Prestige 21 Instrument) with the KBr pellet method and SEM (EVO LS15 OXFORD X-act Scanning Electron Microscope) and EDX studies.

\section{Encapsulation and Characterization}

In the encapsulation of cisplatin drug into the $\mathrm{ZnO}$ nanoparticle, $0.50 \mathrm{~g}$ of $\mathrm{ZnO}$ nanoparticles were dispersed in a $50 \mathrm{~mL}$ of cisplatin injection solution and kept stirring for 24 hours to facilitate cisplatin encapsulation. The product was subsequently separated by centrifuging and washed several times with distilled water and dried in a vacuum oven at $60{ }^{\circ} \mathrm{C}$ for two days. The encapsulation of cisplatin was confirmed by the X-ray fluorescence (XRF) and Fourier Transform Infrared (FT-IR) Spectroscopy, Scanning Electron Microscopy (SEM) and Energy Dispersive X-ray (EDX) analysis of the products obtained.

\section{Release Kinetics of Encapsulated product}

Cisplatin encapsulated PZnO NPs (0.20 g each) were placed in cellulose dialysis tubes (molecular size cut off of 11000 ) and were placed in beakers containing $200 \mathrm{~mL}$ of buffer solutions with $\mathrm{pH}$ values of 4.0, 5.0, 6.0, 7.0, and 8.0 and placed on a thermostatic shaker maintained at $37{ }^{\circ} \mathrm{C}$ and $100 \mathrm{rpm} .10 \mathrm{~mL}$ of supernatant solution was withdrawn at one hour time intervals for 7 hours and also at 24 hours, while an equal volume of fresh buffer solutions was added to maintain the constant volume. Platinum content of the buffer supernatant was determined using Atomic Emission Spectroscopy (AES) (Dunuweera and Rajapakse, 2016). The calibration curve was developed in order to find the concentration of platinum which is released by the encapsulated product using standard solutions made from $40 \mathrm{mg} \mathrm{L}^{-1}$ standard cisplatin solution.

\section{RESULTS AND DISCUSSION}

The particle size analysis was carried out using LASER light scattering based Particle Size Analysis. The instrument gives the plot of the hydrodynamic radius of the colloidal particles in the suspension which is represented in the $\mathrm{x}$-axis of the plot as shown in Figure 3. The $y$-axis of the plot represents the parameter called Q3\% which represents the percentage of particles with a given hydrodynamic radius. It can be inferred that the colloidal solution contains 
PZnO NPs with sizes varying in a wide range of $20 \mathrm{~nm}$ to $1704 \mathrm{~nm}$ with an optimum value of $52 \mathrm{~nm}$ above a $90 \%$ confidence level. Also, $10 \%$ of particles are smaller than the $41 \mathrm{~nm}$, half are smaller than the $105 \mathrm{~nm}$ and half are greater than the $105 \mathrm{~nm}, 90 \%$ of the particles are smaller than the $423 \mathrm{~nm}$.

The PZnO NPs synthesized in this work was characterized using Powder X-Ray Diffraction and the $\mathrm{X}$-Ray Diffractogramme obtained is shown in Figure 4a. The sample contains an essentially hexagonal wurtzite structure as the major phase. The main characteristic peaks of hexagonal wurtzite are at $2 \theta$ of $31.718^{\circ}, 34.423^{\circ}, 36.225^{\circ}$, $47.644^{\circ}, 56.658^{\circ}, 62.824^{\circ}, 66.430^{\circ}, 67.848^{\circ}, 68.978^{\circ}$ which correspond to the diffractions from (100), (002), (101), (102), (110), (103), (200), (112) and (201) crystallographic planes (JCPDS card number 36-1451), which can be clearly seen (Wojnarowicz et al., 2016). Application of the Debye-Scherrer Equation to the major PXRD peak gives the crystallite size to be $18.87 \mathrm{~nm}$. According to Figure $4 \mathrm{~b}$ hexagonal wurtzite structure of zinc oxide nanoparticles have not changed after encapsulation and also strongest peaks observed at $2 \theta$ values lie approximately at the same previous $2 \theta$ values (Wojnarowicz et al., 2016). The presence of cisplatin cannot be determined from PXRD as cisplatin is present in a non-crystalline form in the restricted environment of zinc oxide pores.

As evidenced from the FT-IR spectrum, provided in Figure $5 \mathrm{a}$, the absorption band at $475 \mathrm{~cm}^{-1}$ is due to $\mathrm{Zn}-\mathrm{O}$ vibration which confirms the presence of the $\mathrm{ZnO}$ (Rana et al., 2016). Around $3500 \mathrm{~cm}^{-1}$ a broadband appears which is due to $\mathrm{O}-\mathrm{H}$ starching vibration of $\mathrm{H}_{2} \mathrm{O}$ vapor adsorbed onto PZnO NPs which can take place due to its hydrophilic nature and other bands appear due to impurities of fused $\mathrm{KBr}$. The FT-IR spectrum of the encapsulated product obtained (Figure: $5 \mathrm{~b}$ ) clearly shows the presence of N-H anti symmetric and symmetric stretching vibration at 3334 $\mathrm{cm}^{-1}$ and $3477 \mathrm{~cm}^{-1}$, respectively (FT-IR spectrum of the encapsulated product was recorded after drying at $60{ }^{\circ} \mathrm{C}$ for 2 days in vacuum oven ). It also contains the vibration band of $\mathrm{Zn}-\mathrm{O}$ at $488 \mathrm{~cm}^{-1}$. The FT-IR data suggest the encapsulation of cisplatin in pours zinc oxide nanoparticles. Due to encapsulation, Zn-O vibration band has been shifted from $475 \mathrm{~cm}^{-1}$ to $488 \mathrm{~cm}^{-1}$.

XRF and FT-IR are both bulk analytical techniques which can measure the composition of bulk samples. However, SEM analysis is a surface analytical technique detecting a few micrometer widths from the surface and therefore EDX detects the elements present close to the surface of the porous zinc oxide nanoparticles. EDX is also an analytical technique used for elemental analysis and relies on the interaction of backscattered X-ray radiation and a sample. The capacity for characterization in EDX is high because of the fact that each element has a unique atomic structure, allowing a unique set of peaks on the electromagnetic emission spectrum. PZnO NPs consists of zinc $(\mathrm{Zn})$ and oxygen $(\mathrm{O})$ and the presence of $\mathrm{Zn}$ and $\mathrm{O}$ in the EDX spectrum as shown in Figure 6 is a clear indication that the presence of $\mathrm{ZnO}$ in the sample. Also, peak possibly omitted at $0.272 \mathrm{keV}$ may be due to carbon (C) because we used zinc acetate.dihydrate $\left[\mathrm{Zn}\left(\mathrm{CH}_{3} \mathrm{COO}\right)_{2} .2 \mathrm{H}_{2} \mathrm{O}\right]$ for the synthesis and also hydrogen $(\mathrm{H})$ cannot be detected using EDX. The SEM images of porous zinc oxide nanoparticles are shown in Figure 7: (a), (b), (c) and (d). As is evident from particle size determination of the suspension, discrete particles are present in the suspension. But according to these SEM images, it can be clearly seen that the zinc oxide sample contains more of microparticles rather than nanoparticles because the aggregation of PZnO NPs by solid-solid interactions to form more stable microparticles. Also, the SEM images clearly show that the sample contains spherical shape particles and the morphology of the PZnO NPs shows a good porous nature which can give a clear indication that these particles, though larger in size, can be used as a host material for encapsulation of cisplatin. The SEM images obtained for PZnO NPs after encapsulation is shown in Figure 7: (e) and (f). They show less porosity and

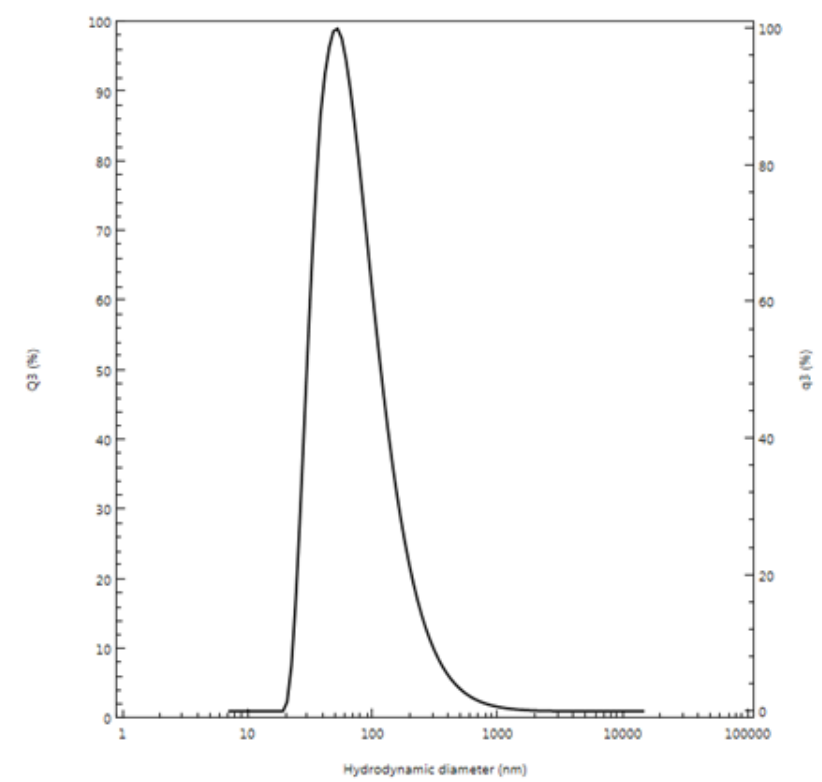

Figure 3: Particle Size Distribution of synthesized PZnO NPs. 


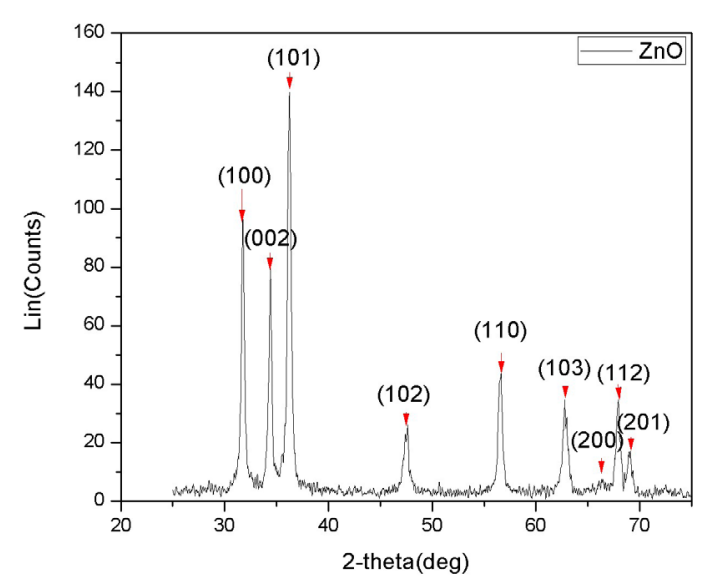

(a)

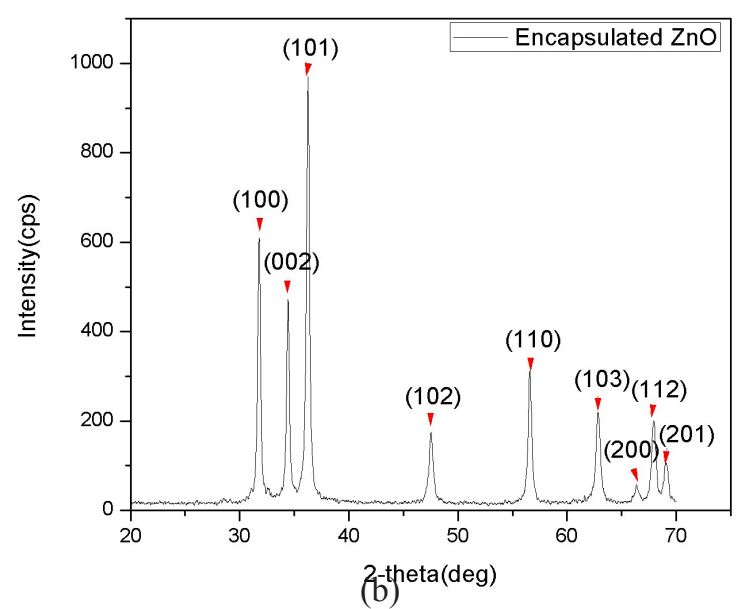

Figure 4: (a) PXRD pattern obtained for synthesized PZnO NPs (b) PXRD pattern obtained for cisplatin encapsulated zinc oxide nanoparticles.

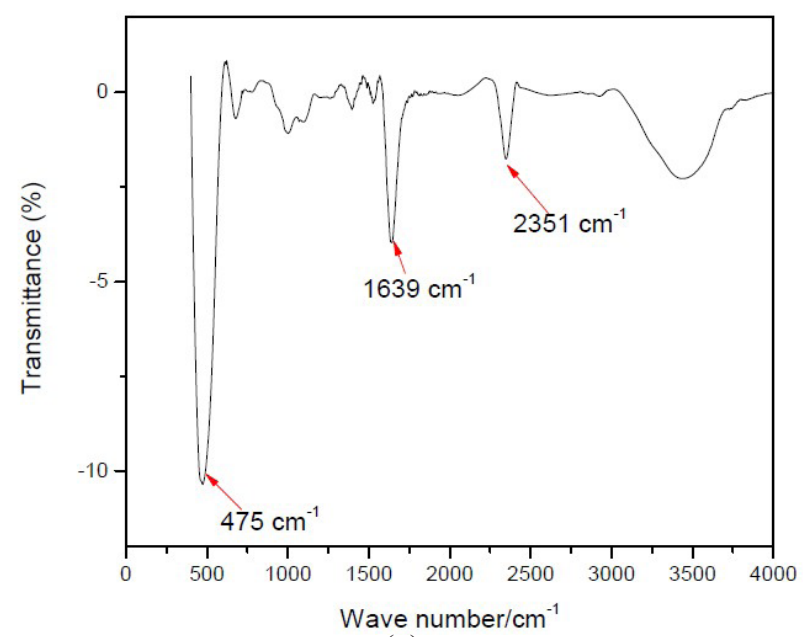

(a)

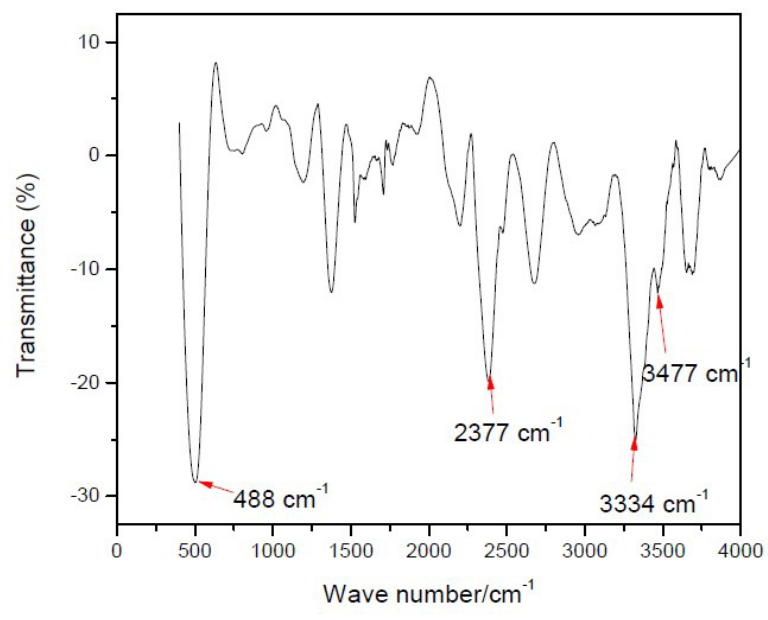

(b)

Figure 5: (a) FT-IR spectrum of the synthesized zinc oxide nanoparticles. (b) FT-IR spectrum of cisplatn encapsulated ZnO nanoparticles.

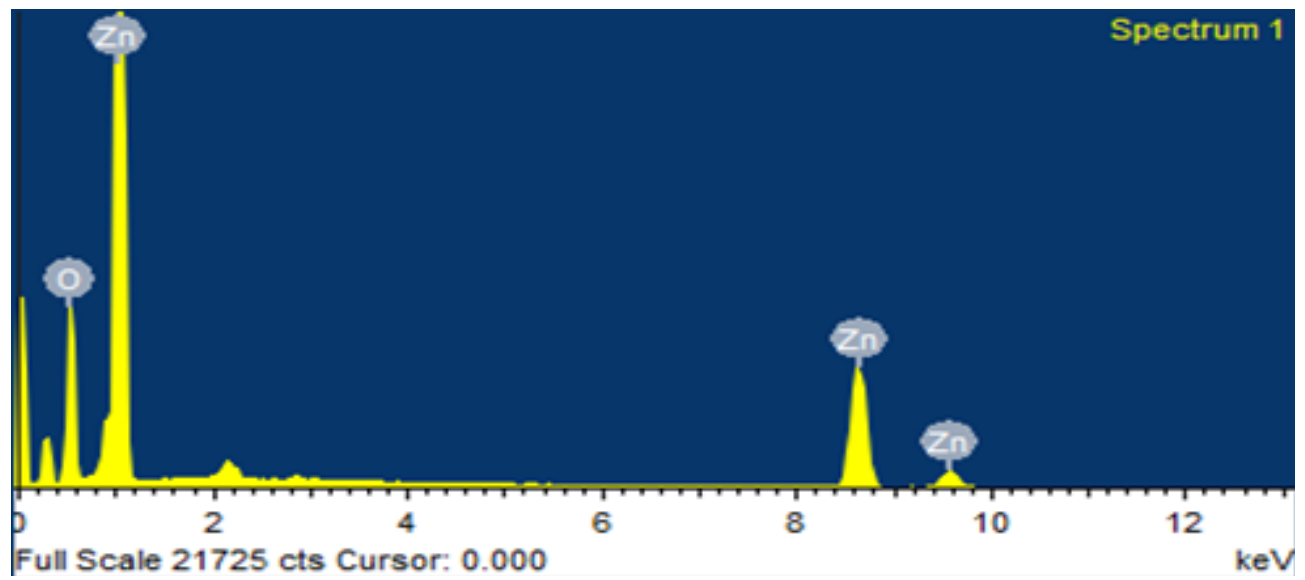

Figure 6: EDX spectrum of synthesized PZnO NPs. 
somewhat changed the morphology of the particles surface which may be an indication that the encapsulation process has successfully taken place.

XRF provides information on the quantitative and qualitative determination of the types of elements that are present in a sample. Our XRF machine is incapable of detecting elements with atomic number less than 13. Therefore, it shows that the product formed is free of impurities containing the element with an atomic number higher than 13. The XRF spectra of the cisplatin encapsulated $\mathrm{ZnO}$ NPs product, shown in Figure 8, clearly indicates the presence of $\mathrm{Zn}, \mathrm{Pt}$, and $\mathrm{Cl}$ with the Pt: $\mathrm{Cl}$ atomic ratio of approximately $1: 2$. However, XRF is incapable of detecting $\mathrm{N}$ and $\mathrm{H}$. 1:2 $\mathrm{Pt}: \mathrm{Cl}$ ratio is the correct atomic ratio of $\mathrm{Pt}$ and $\mathrm{Cl}$ in cisplatin and hence $\mathrm{XRF}$ data suggest the presence of cisplatin in pours ZnO NPs. The determination of encapsulation efficiency was done by conducting AES analysis on the supernatant solution to obtain the platinum concentration corresponding to the concentration of cisplatin. Equation (1) is used to calculate the encapsulation efficiency.
$E=\frac{\mathrm{C}_{0}-\mathrm{C}_{1}}{\mathrm{C}_{0}} \times 100 \%$

Where, $\mathrm{E}=$ Encapsulation Efficiency $(\%), \mathrm{C}_{0}=$ Initial Cisplatin Concentration, $\mathrm{C}_{1}=$ Cisplatin Residual concentration. Calculated cisplatin encapsulation efficiency is $50.52 \%$. In general, cancer cells have a low $\mathrm{pH}$ value compared to normal cells. There are many explanations as to why this is so, but it is usually due to the higher rate of cell differentiation. Erratic and uncontrolled growth occurs where the supply of oxygen is low. As a result, the tumor cells have no choice but to undergo anaerobic respiration, which leads to the formation of lactic acid. This process changes the tumor cell's $\mathrm{pH}$ profile $(\mathrm{pH}$ is lower between 5.0 and 6.0). This change in $\mathrm{pH}$ can be used to initiate a targeted drug delivery mechanism and to slowly release the drug under acidic pH conditions. According to Figure 9(a), synthesized porous zinc oxide nanoparticles may be stable in all $\mathrm{pH}$ values. However, the released percentage slightly increase at $\mathrm{pH}=6.0$. Here, we can ignore the release profile obtained at $\mathrm{pH}=8.0$ because usually, the human body does not attain $\mathrm{pH}=8.0$ basicity in any organ or any part.
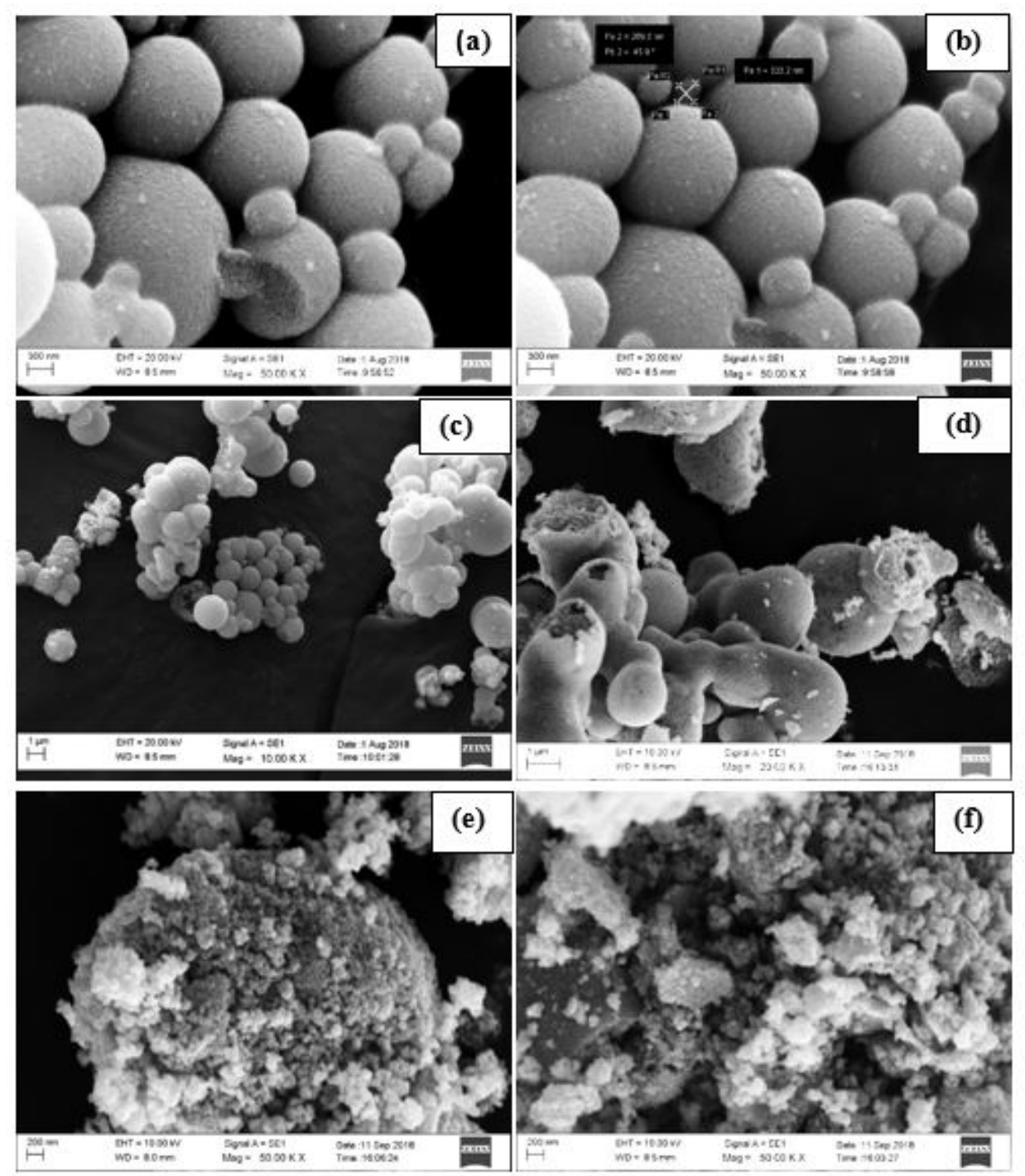

Figure 7: (a), (b), (c), (d) are SEM images of aggregated synthesized PZnO NPs and (e), (f) are SEM images of cisplatin encapsulated PZnO NPs. 


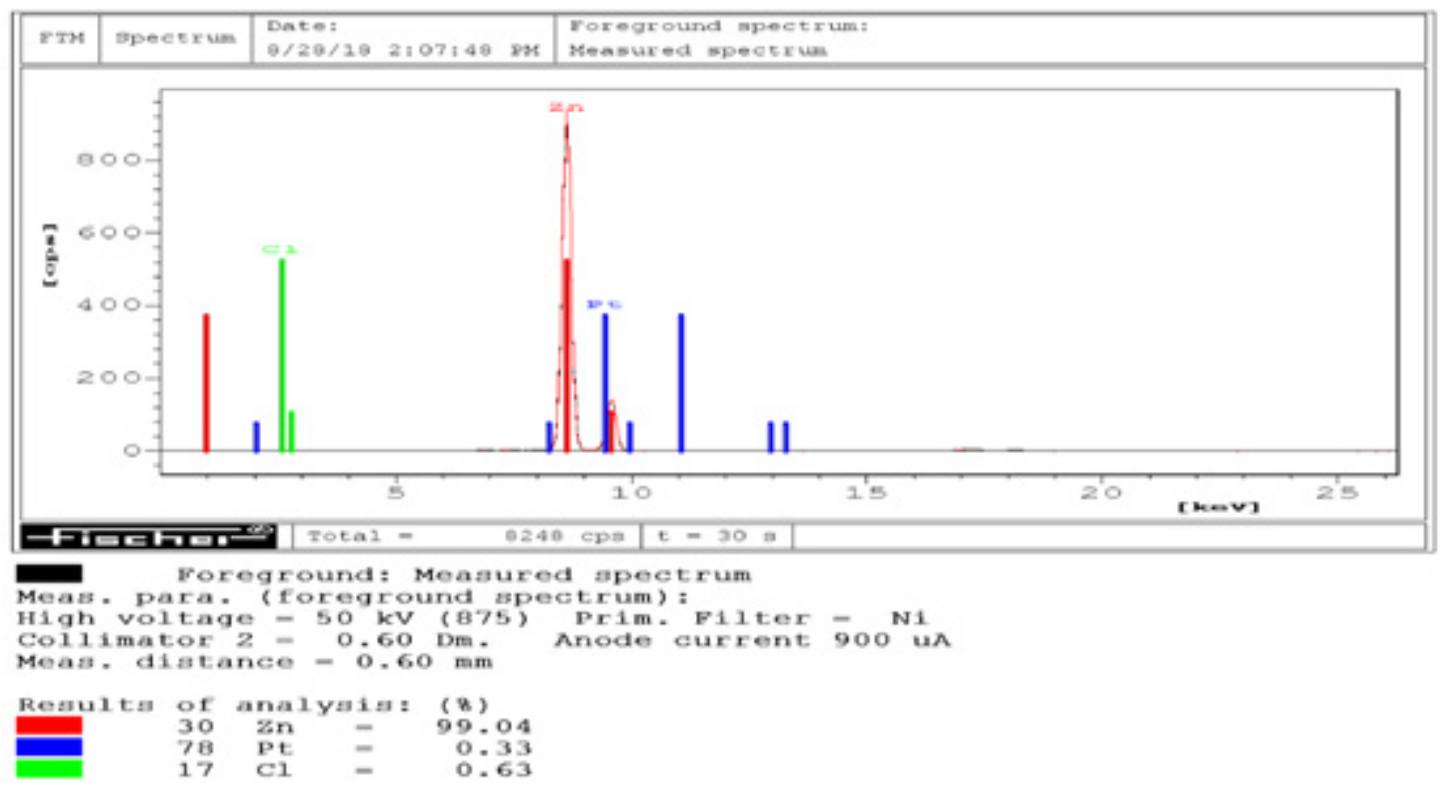

Figure 8: XRF spectra of cisplatin encapsulated $\mathrm{ZnO}$ nanoparticles.

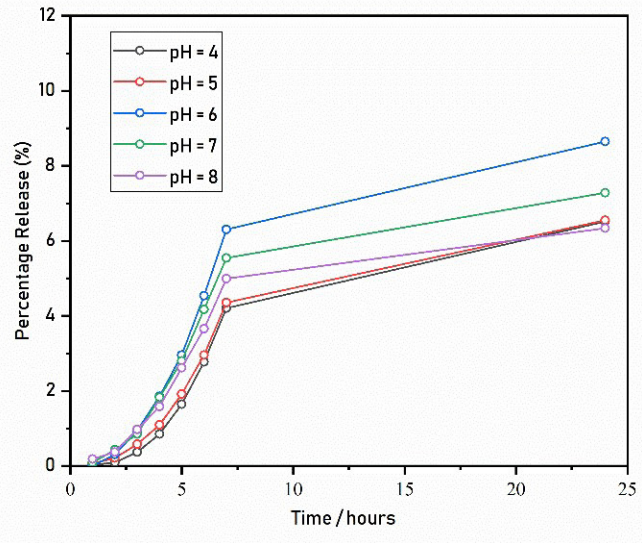

(a)

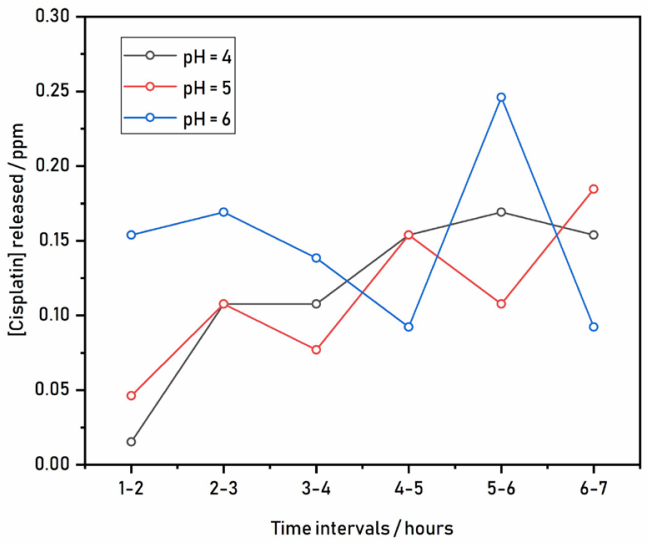

(b)

Figure 9: (a) Anticancer drug release profile for each different $\mathrm{pH}$ and time intervals (b) Cisplatin concentration released during first 7 hours for acidic $\mathrm{pH}$ values.

However, if we consider the drug release profiles of $\mathrm{pH}$ $=4.0,5.0,6.0$, and 7.0, it can be observed that during the first 7 hours which is crucial when it comes to anticancer drug delivery, the release of cisplatin from PZnO NPs is in a very slight amount. Even at $\mathrm{pH}=7.0$ (neutral $\mathrm{pH}$ ), we can see only $5.54 \%$ of total drug encapsulated in $\mathrm{PZnO}$ NPs is released after 7 hours. pH of healthy tissues in the human body is about 6.8-7.3 and it can be inferred that the release of drug from PZnO NPs will not give harmful side effect in comparison to the drug administered in free form without encapsulation. Therefore, we can get an indication that the side effects can be reduced up to a certain extent by encapsulation. Further, during acidic $\mathrm{pH}$ values, the release of cisplatin from $\mathrm{PZnO}$ NPs is slower. This is may be due to the fact that PZnO NPs is stable at low $\mathrm{pH}$ values. This property can be taken into a positive use by selectively binding PZnO NPs encapsulated cisplatin to the cancer cells, then, the obtained slow release can be used to reduce the dosage cycles given for cancer treatment which is also a positive factor to reduce toxicity and side effects for the body by the drug. PZnO NPs can release the drug in small quantities within a longer period, preventing toxicity risks. Since we used $1000 \mathrm{ppm}$ of cisplatin solution in this encapsulation experiment and around $505 \mathrm{ppm}$ were encapsulated, the concentration of cisplatin encapsulated can be considered acceptable for release over a long period of time. Considering the release of the drug during the first 7 hours at acidic $\mathrm{pH}$ values, as shown in Figure 9(b), we can see that the release is not completely uniform. At $\mathrm{pH}$ $=5.0$ we can see a release which fluctuates negatively and positively it may be due to different porosity of synthesized zinc oxide nanoparticles, higher porosity in some particles contains more cisplatin, therefore, an average uniform release is observed. But, at $\mathrm{pH}=6.0$ and 4.0 , we can see the almost uniform release of cisplatin except during 5-6 hours at $\mathrm{pH}=6.0$. At these $\mathrm{pH}$ values, the particles are more stable and therefore the only diffusion takes place which explains the very slow release of cisplatin concentration 
encapsulated.

\section{CONCLUSION}

PXRD and FT-IR studies have proven that the hexagonal wurtzite structure of porous zinc oxide nanoparticles was produced using the forced hydrolysis reaction of $\mathrm{Zn}\left(\mathrm{CH}_{3} \mathrm{COO}\right)_{2} .2 \mathrm{H}_{2} \mathrm{O}$ with deionized water in diethylene glycol (DEG) media. FT-IR studies show an interaction between porous zinc oxide nanoparticles and the anticancer drug cisplatin. SEM images show that the morphological differences between porous zinc oxide nanoparticles and the anticancer drug cisplatin encapsulated product and also it showed that the spherical morphology of zinc oxide nanoparticles. PXRD studies have illustrated that anticancer drug encapsulated $\mathrm{ZnO}$ NPs retain with same wurtzite structure. EDX provided a clear indication that porous $\mathrm{ZnO}$ NPs do not contain any heavy metals or unwanted impurities and also EDX spectrum gives clear evidence to prove that cisplatin is present in nanoparticles. According to particle size analysis data, average particle size of $\mathrm{ZnO}$ NPs is $52 \mathrm{~nm}$. Cisplatin was successfully encapsulated in porous $\mathrm{ZnO}$ NPs which retains its chemical identity within the confined environment as also explained by XRF studies. By analyzing the data obtained for in vitro studies, it can be concluded that the release of cisplatin adsorbed by porous $\mathrm{ZnO}$ NPs slightly increases at $\mathrm{pH}=6$. But during the first seven hours, very mild release of cisplatin was shown all $\mathrm{pH}$ values. $\mathrm{pH}$ of healthy tissues in the human body is about 6.8-7.3 and it can be inferred that the release of drug from PZnO NPs will not give harmful side effect in comparison to the drug administered in free form without encapsulation. Therefore, it gives an indication that the side effects can be reduced up to a certain extent by encapsulation. When considering the all of things, the encapsulated porous $\mathrm{ZnO}$ NPs can be delivered to cancer cells in a targeted manner and cisplatin can be released in minimum amounts at the vicinity of the cancer cells which can reduce the dosage cycles given at a time period for effective destruction of cancer cells.

\section{ACKNOWLEDGEMENT}

The authors wish to thank the Department of Chemistry, Faculty of Science, University of Peradeniya for all the facilities provided.

\section{DECLARATION OF CONFLICT OF INTEREST}

The Authors declare that there is no conflict of interest.

\section{REFERENCES}

Abdulla, M., Biorklund, A., Mathur, A. and Wallenius, K. (1979). Zinc and copper levels in whole blood and plasma from patients with squamous cell carcinomas of head and neck. Journal of surgical oncology, 12(2): 107-113. DOI: https://doi.org/10.1002/jso.293 0120203 .

Abercrombie, M., and Ambrose, E.J. (1962). The surface properties of cancer cells: a review. Cancer research, 22(5 Part 1): 525-548.

Abnet, C.C., Lai, B., Qiao, Y.L., Vogt, S., Luo, X.M., Taylor, P.R. and Dawsey, S.M. (2005). Zinc concentration in esophageal biopsy specimens measured by X-ray fluorescence and esophageal cancer risk. Journal of the National Cancer Institute, 97(4): 301-306. DOI: https://doi.org/10.1093/jnci/dji042.

Ashrafi, A.B.M.A. and Jagadish, C. (2007). Review of zincblende $\mathrm{ZnO}$ : Stability of metastable $\mathrm{ZnO}$ phases. Journal of Applied Physics, 102(7): 1-12. DOI: https://doi.org/10.1063/1.2787957.

Astolfi, L., Ghiselli, S., Guaran, V., Chicca, M., Simoni, E.D.I., Olivetto, E. and Martini, A. (2013). Correlation of adverse effects of cisplatin administration in patients affected by solid tumours: A retrospective evaluation. Oncology reports, 29(4): 1285-1292. DOI: https://doi.org/10.3892/or.2013.2279.

Beletsi, A., Klepetsanis, P., Ithakissios, D.S., Kounias, S., Stavropoulos, A. and Avgoustakis, K. (2008). Simultaneous optimization of cisplatin-loaded PLGAmPEG nanoparticles with regard to their size and drug encapsulation. Current Nanoscience, 4(2): 173-178. DOI: https://doi.org/10.2174/157341308784340895.

Biplab, K.C., Paudel, S.N., Rayamajhi, S., Karna, D., Adhikari, S., Shrestha, B.G. and Bisht, G. (2016). Enhanced preferential cytotoxicity through surface modification: synthesis, characterization and comparative in vitro evaluation of TritonX-100 modified and unmodified zinc oxide nanoparticles in human breast cancer cell (MDA-MB-231). Chemistry Central Journal, 10(1): 1-10. DOI: https://doi. org/10.1186/s13065-016-0162-3.

Degen, A. and Kosec, M. (2000). Effect of pH and impurities on the surface charge of zinc oxide in aqueous solution. Journal of the European Ceramic Society, 20(6): 667-673. DOI: https://doi.org/10.1016/ S0955-2219(99)00203-4.

Dunuweera, S.P. and Rajapakse, R.M.G. (2016). Synthesis of unstable vaterite polymorph of hollow calcium carbonate nanoparticles and encapsulation of the anticancer drug cisplatin. Journal of Advances in Medical and Pharmaceutical Sciences, 10(4): 1-10. DOI: https://doi.org/10.9734/JAMPS/2016/29784.

Dunuweera, S.P. and Rajapakse, R.M.G. (2017). Encapsulation of anticancer drug cisplatin in vaterite polymorph of calcium carbonate nanoparticles for targeted delivery and slow release. Biomedical Physics \& Engineering Express, 4(1), 015017. DOI: https://doi. org/10.1088/2057-1976/aa9719.

Eixenberger, J.E., Anders, C.B., Hermann, R.J., Brown, R.J., Reddy, K.M., Punnoose, A. and Wingett, D.G. (2017). Rapid dissolution of $\mathrm{ZnO}$ nanoparticles induced by biological buffers significantly impacts cytotoxicity. Chemical research in toxicology, 30(8): 1641-1651. DOI: https://doi.org/10.1021/acs. chemrestox.7b00136.

Fong, L.Y., Lau, K.M., Huebner, K. and Magee, P.N. (1997). Induction of esophageal tumors in zinc-deficient rats by single low doses of $\mathrm{N}$-nitrosomethylbenzylamine (NMBA): analysis of cell proliferation, and mutations in H-ras and p53 genes. Carcinogenesis, 18(8): 14771484. DOI: https://doi.org/10.1093/carcin/18.8.1477.

Fong, L.Y., Li, J.X., Farber, J.L. and Magee, P.N. (1996). Cell proliferation and esophageal carcinogenesis in the 
zinc-deficient rat. Carcinogenesis, 17(9): 1841-1848. DOI: https://doi.org/10.1093/carcin/17.9.1841.

Grattan, B.J. and Freake, H.C. (2012). Zinc and cancer: implications for LIV-1 in breast cancer. Nutrients, 4(7): 648-675. DOI: https://doi.org/10.3390/nu4070648.

Gryparis, E.C., Mattheolabakis, G., Bikiaris, D. and Avgoustakis, K. (2007). Effect of conditions of preparation on the size and encapsulation properties of PLGA-mPEG nanoparticles of cisplatin. Drug delivery, 14(6): 371-380. DOI: https:/doi. org/10.1080/10717540701202937.

Inutsuka, S. and Araki, S. (1978). Plasma copper and zinc levels in patients with malignant tumors of digestive organs. Clinical evaluation of the $\mathrm{Cu} /$ $\mathrm{Zn}$ ratio. Cancer, 42(2): 626-631. DOI:https://doi. org/10.1002/1097-0142(197808)42:2<626::AIDCNCR2820420232>3.0.CO;2-F.

Jiang, J., Pi, J. and Cai, J. (2018). The advancing of zinc oxide nanoparticles for biomedical applications. Bioinorganic chemistry and applications, 2018. DOI: https://doi. org/10.1155/2018/1062562.

Lee, D.H., Anderson, K.E., Harnack, L.J., Folsom, A.R. and Jacobs Jr, D.R. (2004). Heme iron, zinc, alcohol consumption, and colon cancer: Iowa Women's Health Study. Journal of the National Cancer Institute, 96(5): 403-407. DOI: https://doi.org/10.1093/jnci/djh047.

Moezzi, A., McDonagh, A.M. and Cortie, M.B. (2012). Zinc oxide particles: synthesis, properties and applications. Chemical engineering journal, 185: 1-22. DOI: https://doi.org/10.1016/j.cej.2012.01.076.

Newberne, P.M., Broitman, S. and Schrager, T.F. (1997). Esophageal carcinogenesis in the rat: zinc deficiency, DNA methylation and alkyltransferase activity. Pathobiology, 65(5): 253-263. DOI: https:// doi.org/10.1159/000164136.

Oun, R., Moussa, Y.E. and Wheate, N.J. (2018). The side effects of platinum-based chemotherapy drugs: a review for chemists. Dalton transactions, 47(19): 6645-6653. DOI: https://doi.org/10.1039/C8DT00838H.

Özgür, Ü., Alivov, Y.I., Liu, C., Teke, A., Reshchikov, M., Doğan, S. and Morkoç, A.H. (2005). A comprehensive review of $\mathrm{ZnO}$ materials and devices. Journal of applied physics, 98(4): 3-12. DOI: https://doi. org/10.1063/1.1992666.

Prasad, A.S. (1993). Clinical spectrum of human zinc deficiency. Biochemistry of zinc, Springer, Boston, MA, pp. 219-258. DOI: https://doi.org/10.1007/978-14757-9444-1 11.

Prasad, A.S. (1998). Zinc in human health: an update. The Journal of Trace Elements in Experimental Medicine: The Official Publication of the International Society for Trace Element Research in Humans, 11(2-3): 63-87. DOI: https://doi.org/10.1002/(SICI)1520670X(1998)11:2/3<63::AID-JTRA2>3.0.CO;2-5.

Prasad, A.S., Beck, F.W., Doerr, T.D., Shamsa, F.H., Penny, H.S., Marks, S.C. and Mathog, R.H. (1998). Nutritional and zinc status of head and neck cancer patients: an interpretive review. Journal of the American College of Nutrition, 17(5): 409-418. DOI: https://doi.org/10.1080 /07315724.1998.10718787.

Qu, F. and Morais, P.C. (2001). The pH dependence of the surface charge density in oxide-based semiconductor nanoparticles immersed in aqueous solution. IEEE transactions on magnetics, 37(4): 2654-2656. DOI: 10.1109/20.951264.

Rajapakse, R.M.G. and Dunuweera, S.P. (2017). Discovery, chemistry, anticancer action and targeting of cisplatin. Int. J. Clin. Oncol. Cancer Res, 2(3): 65-74. DOI: 10.11648/j.ijcocr.20170203.13.

Rana, N., Chand, S. and Gathania, A.K. (2016). Green synthesis of zinc oxide nano-sized spherical particles using terminalia chebula fruits extract for their photocatalytic applications. International Nano Letters, 6(2): 91-98. DOI: https://doi.org/10.1007/ s40089-015-0171-6.

Ranathunge, T.A., Karunaratne, D.G.G.P., Rajapakse, R.M.G. and Watkins, D.L. (2019). Doxorubicin loaded magnesium oxide nanoflakes as $\mathrm{pH}$ dependent carriers for simultaneous treatment of cancer and hypomagnesemia. Nanomaterials, 9(2): 208. DOI: https://doi.org/10.3390/nano9020208.

Rasmussen, J.W., Martinez, E., Louka, P. and Wingett, D.G. (2010). Zinc oxide nanoparticles for selective destruction of tumor cells and potential for drug delivery applications. Expert opinion on drug delivery, 7(9): 1063-1077. DOI: https://doi.org/10.1517/17425247.20 10.502560 .

Sadler, P.J. and Guo, Z. (1998). Metal complexes in medicine: design and mechanism of action. Pure and Applied Chemistry, 70(4): 863-871. DOI: https://doi. org/10.1351/pac199870040863.

Vallabhapurapu, S.D., Blanco, V.M., Sulaiman, M.K., Vallabhapurapu, S.L., Chu, Z., Franco, R.S. and Qi, X. (2015). Variation in human cancer cell external phosphatidylserine is regulated by flippase activity and intracellular calcium. Oncotarget, 6(33): 34375-34388. DOI: 10.18632/oncotarget.6045.

Weerasuriya, D.R.K., Wijesinghe, W.P.S.L. and Rajapakse, R.M.G. (2017). Encapsulation of anticancer drug copper bis (8-hydroxyquinoline) in hydroxyapatite for $\mathrm{pH}$ sensitive targeted delivery and slow release. Materials Science and Engineering: C, 71: 206-213. DOI: https:// doi.org/10.1016/j.msec.2016.10.010.

Wojnarowicz, J., Opalinska, A., Chudoba, T., Gierlotka, S., Mukhovskyi, R., Pietrzykowska, E. and Lojkowski, W. (2016). Effect of water content in ethylene glycol solvent on the size of $\mathrm{ZnO}$ nanoparticles prepared using microwave solvothermal synthesis. Journal of Nanomaterials, 2016, DOI: http://dx.doi. org/10.1155/2016/2789871. 